\title{
Uso do gérmen de milho desengordurado, com e sem adição de um complexo enzimático, em dietas para cães
}

[Use of defatted corngerm with and without the addition of an enzyme complex in dog diets]

T.T. Sabchuk, T.S. Bastos, A.S. Komarcheuski, A. Maiorka, A.P. Félix, S.G. Oliveira*

Universidade Federal do Paraná - Curitiba, PR

\section{RESUMO}

Objetivou-se avaliar o coeficiente de digestibilidade aparente (CDA) dos nutrientes, a palatabilidade das dietas e as características fecais de cães alimentados com uma dieta controle e uma dieta contendo $20 \%$ de gérmen desengordurado (GD), com e sem adição de complexo enzimático (amilase, xilanase, betaglucanase e mananase). Para o experimento de digestibidade e das características fecais, foram utilizados 12 cães adultos, distribuídos em delineamento em blocos ao acaso, em esquema fatorial $2 \times 2$ (dieta x enzima). O segundo experimento avaliou a palatabilidade, por meio da primeira escolha e da razão de ingestão (RI) da dieta DC vs. $20 \%$ de GD, utilizando-se 16 cães. O teste de palatabilidade contou com três dias consecutivos, totalizando 48 repetições. A dieta com inclusão de $20 \%$ de GD teve os menores valores de CDA da MS, da EB e da EM $(\mathrm{P}<0,05)$. A inclusão do complexo enzimático melhorou o CDA da MS, da EB e da EM $(\mathrm{P}<0,05)$. Não foram observadas diferenças nas características fecais $(\mathrm{P}>0,05)$. Em relação à palatabilidade, os cães preferiram a dieta $20 \%$ de $\mathrm{GD}$, tanto na primeira escolha como na $\mathrm{RI}(\mathrm{P}<0,05)$. A inclusão de enzimas às dietas melhora a digestibilidade dos nutrientes e da EM, sendo um aditivo com potencial uso na alimentação de cães.

Palavras-chave: ácido siálico, digestibilidade, escore fecal, enzimas, nutrição de cães

\begin{abstract}
The objective was to evaluate the apparent digestibility coefficient (ADC) of nutrients, diet palatability and fecal characteristics of dogs fed diets containing degreased germ (DG), and a control diet (DC) - both with and without the addition of enzyme complex (amylase, xylanase, betaglucanase and mananase). For the digestibility and fecal characteristics experiment 12 adult dogs were used, distributed in a randomized block design, in a $2 \times 2$ factorial scheme (diet $x$ enzyme). The second experiment evaluated palatability using the first choice and ingestion ratio (IR) of DC diet vs. $20 \% \mathrm{gD}$, using 16 dogs. The palatability test had three consecutive days, totaling 48 repetitions. The diet with inclusion of $20 \% D G$ had the lowest ADC values of DM, GE and $M E(P<0.05)$. Inclusion of the enzyme complex improved ADC of DM, GE and ME $(P<0.05)$. No differences in fecal characteristics were observed $(P>0.05)$. Regarding palatability, dogs preferred the $20 \%$ DG diet in both first choice and IR $(P<0.05)$. Inclusion of enzymes in diets improves nutrient digestibility and $M E$, being an additive with potential use in dog food.
\end{abstract}

Keywords: dog nutrition, sialic acid, digestibility, fecal score, enzymes

\section{INTRODUÇÃO}

A produção de alimentos para animais de companhia vem crescendo no Brasil, o que faz com que a indústria absorva uma ampla gama de coprodutos com densidades nutricionais e digestibilidade distintas (Carciofi, 2008). Junto com esse desenvolvimento, pesquisas sobre novas tecnologias com ingredientes econômicos e nutricionalmente viáveis estão sendo

Recebido em 19 de setembro de 2019

Aceito em 25 de agosto de 2020

* Autor para correspondência (corresponding author)

E-mail: sgoliveira@ufpr.br 
aperfeiçoadas. Dessa forma, os estudos sobre novas fontes alternativas de nutrientes abrem oportunidades não somente para refinar as formulações, como também baratear os custos de produção.

Nesse contexto, a partir do milho, um dos grãos mais produzidos no Brasil e no mundo, inúmeros coprodutos industriais são estudados, como o gérmen de milho. Esse ingrediente é obtido após moagem úmida do grão de milho, seguida da secagem, prensagem (Patience et al., 1995) e perfusão por solvente. $\mathrm{O}$ gérmen do milho pode ser considerado uma fonte energética alternativa ao milho na nutrição animal - quando em sua forma integral, pode possuir até $25 \%$ de óleo em sua composição. $\mathrm{O}$ gérmen desengordurado possui, em média, $5,14 \%$ de fibra bruta, podendo variar de acordo com o processamento (Rostagno et al., 2005). De modo geral, quanto maior o teor de fibra, menor será a energia metabolizável da dieta, em função do efeito negativo dos polissacarídeos não amiláceos (PNA) sobre a digestibilidade dos nutrientes (Sabchuk et al., 2017), o que pode limitar sua utilização na nutrição canina.

Sabendo disso, a inclusão de enzimas exógenas (em especial xilanases, ou complexos enzimáticos) associadas ao uso do gérmen de milho mostra-se uma alternativa para minimizar a influência negativa dos PNA sobre a digestibilidade dos nutrientes, melhorando o valor nutricional desse ingrediente (Twomey et al., 2003; Félix et al., 2012; Cowieson e Adeola, 2005). Dessa forma, o objetivo do presente estudo foi avaliar a digestibilidade dos nutrientes, as características fecais e a palatabilidade da dieta de cães com a inclusão de $20 \%$ de gérmen desengordurado (com e sem adição de complexo enzimático) à dieta em substituição ao milho.

\section{MATERIAL E MÉTODOS}

O experimento foi aprovado pelo Comitê de Ética ao Uso de Animais do Setor de Ciências Agrárias da Universidade Federal do Paraná, Curitiba-PR, Brasil - protocolo 037/2014. O estudo foi dividido em dois experimentos, sendo: digestibilidade e características fecais (experimento I) e palatabilidade da dieta (experimento II). Para o experimento I, foram utilizados 12 cães da raça Beagle, com peso de $10,94 \pm 0,74 \mathrm{~kg}$ e $2 \pm 0,1$ anos de idade. Os cães foram alojados individualmente em baias de alvenaria cobertas por solário $(5 \mathrm{~m}$ de comprimentos x $2 \mathrm{~m}$ de largura).

Foram avaliadas quatro dietas experimentais: controle (DC) e dieta com 20\% de gérmen desengordurado (GD), ambas com e sem inclusão do complexo enzimático, PRECIZYON ${ }^{\mathrm{TM}} \mathrm{X} 550$ $(50 \mathrm{~g} /$ tonelada, $\quad 120.000 \mathrm{u} / \mathrm{g}$ de amilase, 20.000UI/g de xilanase, 7.500UI/g de betaglucanase e $250 \mathrm{UI} / \mathrm{g}$ de mananase, Tab. 1).

Tabela 1. Ingredientes das dietas experimentais

\begin{tabular}{lcc}
\hline \multicolumn{1}{c}{ Ingredientes $(\mathrm{g} / \mathrm{kg})$} & $\mathrm{DC}$ & $20 \% \mathrm{GD}$ \\
\hline Milho & 605,9 & 400,9 \\
Farinha de vísceras de aves & 340,0 & 340,0 \\
Gérmen de milho desengordurado & 0,0 & 20,0 \\
Óleo de vísceras de aves & 25,0 & 30,0 \\
Óleo de soja & 10,0 & 10,0 \\
Cloreto de potássio & 5,5 & 5,5 \\
Sal & 5,0 & 5,0 \\
Premix cães ${ }^{1}$ & 4,0 & 4,0 \\
Cloreto de colina & 2,0 & 2,0 \\
Propionato de cálcio & 2,0 & 2,0 \\
Ácido cítrico & 0,35 & 0,35 \\
BHT & 0,15 & 0,15 \\
BHA & 0,075 & 0,075 \\
\hline
\end{tabular}

${ }^{1}$ Enriquecimento por kg de produto: vitamina A (retinol) = 20.000UI; vitamina D3 = 2000UI; vitamina E (alfa-tocoferol $\alpha)$ =48mg; vitamina K3 = 48mg; vitamina B1=4mg; vitamina B2 =32mg; ácido pantotênico = 16mg; niacina = 56mg; colina $=800 \mathrm{mg}$; como óxido de zinco $\mathrm{Zn}=150 \mathrm{mg}$; Fe como sulfato ferroso $=100 \mathrm{mg}$; $\mathrm{Cu}$ como sulfato de cobre $=$ $15 \mathrm{mg}$; I, tal como iodeto de potássio $=1,5 \mathrm{mg}$; Mn como óxido de manganês $=30 \mathrm{mg}$; Se como selenito de sódio $=$ $0,2 \mathrm{mg}$; antioxidante $=240 \mathrm{mg}$. 
Após a mistura dos ingredientes, as dietas foram moídas em peneiras de $1,0 \mathrm{~mm}$ e extrusadas. As enzimas foram aplicadas em cobertura após a extrusão, juntamente com o palatabilizante. As dietas foram formuladas de acordo com as recomendações da Association of America Feed Control Officials (AAFCO, 2008). Foram analisadas as frações dos polissacarídeos não amiláceos (PNA), FS e FI presentes no gérmen desengordurado (GD) e nas dietas, de acordo com metodologia descrita por Englyst et al. (1982). As composições químicas das dietas e do gérmen desengordurado estão descritas nas Tab. 2 e 3.

Tabela 2. Composição química analisada (\% na matéria seca) do GD e das dietas experimentais

\begin{tabular}{lccccc}
\hline & \multirow{2}{*}{ GD } & \multicolumn{3}{c}{ DC } & \multicolumn{2}{c}{$20 \%$ GD } \\
\cline { 2 - 6 } & & Sem & Com & Sem & Com \\
\hline Matéria seca & 89,26 & 91,06 & 28,50 & 90,95 & 90,93 \\
Proteína bruta & 16,23 & 28,53 & 28,61 & 30,46 & 30,56 \\
Extrato etéreo & 3,45 & 10,95 & 11,06 & 11,81 & 12,09 \\
Matéria mineral & 6,42 & 8,80 & 8,92 & 10,08 & 10,54 \\
Fibra bruta & 4,99 & 1,65 & 1,65 & 1,57 & 1,41 \\
FDN & 30,36 & 18,99 & 21,60 & 21,37 & 20,20 \\
FDA & 6,19 & 2,86 & 2,77 & 2,68 & 2,68 \\
EB (kcal) & 4504,41 & 4096,11 & 4123,28 & 4057,36 & 4176,37 \\
Fibra solúvel & 1,0 & - & - & - & - \\
Fibra insolúvel & 14,3 & - & - & - & - \\
\hline
\end{tabular}

$\overline{\mathrm{FDN}}=$ Fibra em detergente neutro; FDA = fibra em detergente ácido; $\mathrm{EB}=$ energia bruta; $\mathrm{DC}=$ dieta controle $(\mathrm{DC}) ;$ $\mathrm{GD}=$ gérmen desengordurado.

Tabela 3. Análise química das frações dos polissacarídeos não amiláceos (PNA) presentes no gérmen desengordurado (GD) e nas dietas (DC, dieta controle; 20\% de GD, gérmen desengordurado)

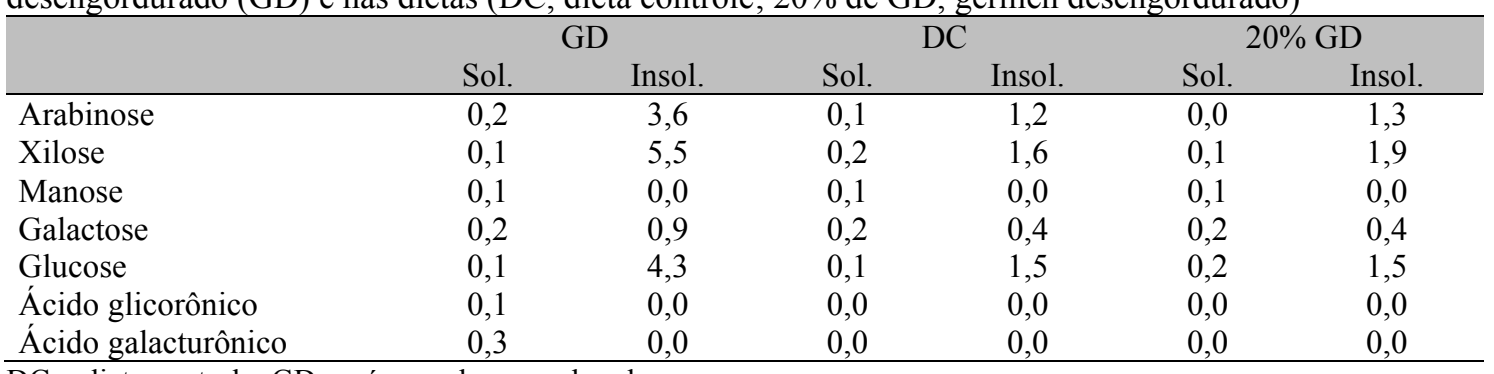

$\mathrm{DC}=$ dieta controle; $\mathrm{GD}=$ gérmen desengordurado.

Os animais receberam as dietas duas vezes ao dia, às oito horas e às $16 \mathrm{~h} 30$, durante 10 dias consecutivos, em quantidades suficientes para atender às exigências energéticas de acordo com o Nutritional Requirements Council (NRC, 2006); a água foi oferecida ad libitum. O ensaio de digestibilidade foi realizado pelo método de coleta total de fezes. Cada período contou com cinco dias de adaptação, seguido por cinco dias de coleta total das fezes, de acordo com as recomendações da Association of American Feed Control Officials (AAFCO, 2008).

As fezes foram coletadas pelo menos duas vezes ao dia, pesadas, identificadas por animal/período e armazenadas em freezer $\left(-14^{\circ} \mathrm{C}\right)$. Para determinação do $\mathrm{pH}$, da amônia e dos ácidos graxos de cadeia curta (AGCC), foram coletadas fezes frescas, no máximo, 15 minutos após a defecação. $\mathrm{O}$ pH fecal foi mensurado por meio de um pHmetro digital (331, Politeste Instrumentos de Teste Ltda., São Paulo, SP, Brasil), utilizandose $2,0 \mathrm{~g}$ de fezes frescas e diluídas com $20 \mathrm{~mL}$ de água destilada. $\mathrm{O}$ teor de amônia nas fezes foi determinado em $5 \mathrm{~g}$ de fezes, as quais foram incubadas em balão de vidro de $500 \mathrm{~mL}$, contendo $250 \mathrm{~mL}$ de água destilada, durante uma hora. Em seguida, três gotas de álcool octílico (1-octanol) e $2 \mathrm{~g}$ de óxido de magnésio foram adicionados à solução, que foi destilada em aparelho macroKjeldahl e recuperada em copo contendo $50 \mathrm{~mL}$ de ácido bórico.

Finalmente, a amônia foi titulada, utilizando-se ácido sulfúrico $0,1 \mathrm{~N}$ normalizado. A concentração de amônia fecal foi calculada como: amoníaco-N 
$(\mathrm{g} / \mathrm{kg})=\mathrm{N} \times$ fator de correção $\times 17 \times($ volume de ácido - em branco) / peso da amostra (g). A concentração de amônia fecal foi corrigida para MS fecal. Os AGCC fecais foram analisados por cromatografia gasosa (SHIMADZU, modelo GC2014, Quioto, Japão). Utilizou-se uma coluna de vidro (Agilent Technologies, HP INNO wax 19091N, Santa Clara, EUA) de 30m de comprimento e $0,32 \mathrm{~mm}$ de largura. $\mathrm{O}$ nitrogênio foi o gás transportador, com uma taxa de fluxo de $3,18 \mathrm{~mL} / \mathrm{min}$. As temperaturas de trabalho foram $200^{\circ} \mathrm{C}$ na injeção, $240^{\circ} \mathrm{C}$ na coluna (na velocidade de $20^{\circ} \mathrm{C} / \mathrm{min}$ ) e $250^{\circ} \mathrm{C}$ no detector de ionização de chama.

$\mathrm{O}$ escore fecal foi avaliado atribuindo-se notas de 1 a 5, de acordo com Carciofi et al. (2009), sendo: 1- fezes pastosas e 5- fezes bem formadas, duras e secas. As dietas e as fezes foram analisadas para determinação dos teores de $\mathrm{S}$ a $105^{\circ} \mathrm{C}, \mathrm{PB}$ (método 954.01), fibra bruta (FB, método 962.10), extrato etéreo em hidrólise ácida (EEA, método 954.02) e matéria mineral (MM, método 942.05), segundo a Association of the Official Analytical Chemists (AOAC, 1995). A energia bruta (EB) foi determinada em bomba calorimétrica (Parr Instrument Co. Model 1261, Moline, IL, EUA). Com base nos resultados laboratoriais obtidos, o coeficiente de digestibilidade aparente (CDA) da MS, da PB, do EEA, da FB, da MM e da MO das dietas experimentais foram calculados por meio da equação:

$\mathrm{CDA} \%=((\mathrm{g}$ nutriente ingerido - $\mathrm{g}$ nutriente excretado) /g nutriente ingerido) x 100 .

A EM foi estimada de acordo com a AAFCO (2008):

EM (kcal.g -1$)=\{$ kcal.g -1 EB ingerida - kcal.g 1 EB excretada nas fezes - [(g PB ingerida - g PB excretada nas fezes) x 1,25 kcal.g -1 ] $\} / g$ ração.

Para análise de ácido siálico, as fezes foram liofilizadas em liofilizador (Alpha 1-4 LO plus, Christ, Osterodeam Hans, Alemanha). Foram utilizados reagentes comometil-2-propanol, ácido periódico, resorcinol, sulfato de cobre e ácido clorídrico. A mensuração foi realizada por espectrofotometria e lida em absorbância de 630nm. A absorbância era diretamente proporcional à presença de ácido siálico na alíquota, seguindo a metodologia proposta por Jourdian et al. (1971), com adaptações para fezes de cães.

O experimento I seguiu delineamento em blocos ao acaso, sendo o período o fator de blocagem. Foram avaliados quatro tratamentos repetidos em dois períodos, com 12 cães em cada período, sendo três cães por tratamento, totalizando seis repetições por tratamento. Os dados foram analisados em esquema fatorial $2 \times 2$ (dieta $\mathrm{x}$ enzima). Os dados foram previamente verificados quanto à sua normalidade (Shapiro-Wilk) e, quando atendida essa premissa, foram submetidos à análise de variância utilizando-se o procedimento GLM do pacote estatístico SAS (SAS Inst. Inc., Cary, NC), e as médias foram comparadas pelo teste de Tukey a 5\% de probabilidade. Quando os dados não apresentaram distribuição normal, foram analisados pelo teste de Kruskal-Wallis, considerando-se $\quad \mathrm{P}<0,05 \quad$ como diferença significativa.

Para avaliar a palatabilidade (experimento II), foram utilizados 16 cães adultos da raça Beagle, comparando-se as dietas em pares: dieta controle (DC) vs. dieta com gérmen desengordurado $(20 \%$ de GD). O teste de palatabilidade teve duração de três dias consecutivos, no qual foram oferecidas as duas dietas em potes separados aos cães. As quantidades oferecidas e as sobras foram quantificadas para calcular a razão de ingestão (RI) e a primeira escolha, definida pelo registro do primeiro pote do qual o animal se aproximou durante a oferta simultânea de alimentos. O delineamento adotado foi o inteiramente ao acaso, totalizando 48 repetições. Os dados da RI foram analisados pelo teste t-Student, e os de primeira escolha pelo teste qui-quadrado, ambos a $5 \%$ de probabilidade.

\section{RESULTADOS}

No presente estudo, foi possível constatar que as dietas com $20 \%$ de GD apresentaram redução no CDA da MS, da EB e da EM ( $<<0,05$, Tab. 4) em relação à DC. Por outro lado, a inclusão do complexo enzimático aumentou os CDA da MS, da EB e da EM $(\mathrm{P}<0,05$, Tab. 4) das dietas avaliadas. 
Tabela 4. Coeficiente de digestibilidade aparente (CDA, \%) da matéria seca (MS), da proteína bruta (PB), da energia bruta $(\mathrm{EB})$ e da energia metabolizável (EM, $\mathrm{kcal} / \mathrm{kg}$ ) de cães adultos alimentados com a dieta controle (DC) e dietas contendo $20 \%$ de gérmen desengordurado (GD)

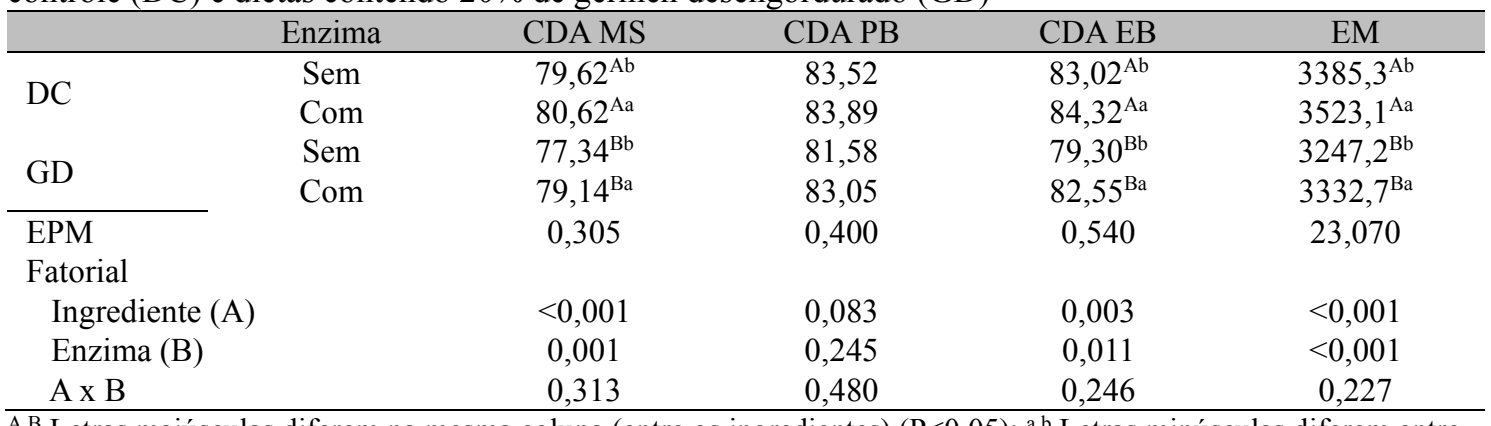

$\overline{\mathrm{A}, \mathrm{B}}$ Letras maiúsculas diferem na mesma coluna (entre os ingredientes) $(\mathrm{P}<0,05) ;{ }^{\mathrm{a}, \mathrm{b}}$ Letras minúsculas diferem entre ter ou não enzima $(\mathrm{P}<0,05)$.

Tanto a inclusão de GD quanto do complexo enzimático não influenciaram o escore fecal, a produção de fezes, o $\mathrm{pH}$, o $\mathrm{NH}_{3}$ e o ácido siálico $(\mathrm{P}>0,05$, Tab. 5). No entanto, foi observado maior teor de MSf com a inclusão do GD $(\mathrm{P}<0,01$, Tab. 5) em relação à DC. Não foi observada interação entre enzima e ingrediente. Além disso, não foram observados efeitos tanto das dietas quanto da inclusão do complexo enzimático em relação à produção dos ácidos graxos de cadeia curta ( $\mathrm{P}$ $<0,05$, Tab. 6), com exceção do ácido propiônico, que reduziu em dietas GD. Quanto ao ensaio de palatabilidade, a dieta com inclusão de GD apresentou maior preferência alimentar e primeira escolha pelos cães $(\mathrm{P}<0,05$, Tab. 7).

Tabela 5. Características fecais de cães recebendo dieta controle (DC), 20\% de gérmen desengordurado (20\% GD) com e sem adição de complexo enzimático

\begin{tabular}{lccccccc}
\hline & Enzima & MSf (\%) & Escore* $^{*}$ & PFMS & pH & $\mathrm{NH}_{3}$ & AS \\
\cline { 1 - 5 } DC & Sem & 37,88 & 3,36 & 6,98 & 6,91 & 0,095 & 0,679 \\
& Com & 37,81 & 3,44 & 6,73 & 6,77 & 0,086 & 0,697 \\
GD & Sem & 40,29 & 3,28 & 7,01 & 6,8 & 0,102 & 0,625 \\
\cline { 1 - 4 } EPM & Com & 40,56 & 3,49 & 6,98 & 6,96 & 0,111 & 0,643 \\
Fatorial & & 0,486 & 0,050 & 0,043 & 0,051 & 0,004 & 0,027 \\
Ingrediente (A) & & 0,007 & - & 0,087 & 0,718 & 0,103 & 0,360 \\
Enzima (B) & & 0,906 & - & 0,082 & 0,900 & 0,985 & 0,750 \\
A x B & & 0,846 & - & 0,179 & 0,159 & 0,327 & 0,992 \\
\hline
\end{tabular}

$\overline{\mathrm{A}, \mathrm{B}}$ Letras maiúsculas diferem na mesma coluna (entre os ingredientes) $(\mathrm{P}<0,05)$; EPM: erro-padrão da média. *Difere pelo teste de Kruskal-Wallis $(\mathrm{P}=0,507)$. MSf = matéria seca fecal $(\%)$; PFMS = produção fecal de matéria seca $\left(\mathrm{gMS} / \mathrm{PC}^{0,75} / \mathrm{d}\right) ; \mathrm{NH}_{3}:=$ nitrogênio amoniacal $(\%) ; \mathrm{AS}=$ ácido siálico $(\mathrm{mg})$.

Tabela 6. Perfil de ácidos graxos de cadeia curta (AGCC) das fezes de cães adultos alimentados com a dieta controle (DC) e dieta contendo 20\% de gérmen desengordurado (GD)

\begin{tabular}{|c|c|c|c|c|c|c|c|c|}
\hline & Enzima & Acético & Propiônico & Butírico & Valérico & Isobutírico & Isovalérico & $\begin{array}{c}\text { AGCC } \\
\text { totais }\end{array}$ \\
\hline \multirow{2}{*}{$\mathrm{DC}$} & Sem & 30,82 & $14,33^{\mathrm{A}}$ & 4,89 & 1,66 & 4,49 & 1,10 & 57,31 \\
\hline & Com & 30,83 & $14,81^{\mathrm{A}}$ & 4,61 & 1,27 & 4,23 & 0,94 & 56,71 \\
\hline \multirow{2}{*}{ GD } & Sem & 27,62 & $10,43^{\mathrm{B}}$ & 4,33 & 1,49 & 4,55 & 1,08 & 49,53 \\
\hline & Com & 29,71 & $11,22^{\mathrm{B}}$ & 4,92 & 1,63 & 4,74 & 1,47 & 53,71 \\
\hline \multicolumn{2}{|c|}{$\begin{array}{l}\text { EPM } \\
\text { Fatorial }\end{array}$} & 1,543 & 0,902 & 0,257 & 0,094 & 0,315 & 0,081 & 2,67 \\
\hline \multicolumn{2}{|c|}{ Ingrediente (A) } & 0,514 & 0,043 & 0,778 & 0,615 & 0,673 & 0,106 & 0,344 \\
\hline \multicolumn{2}{|c|}{ Enzima (B) } & 0,750 & 0,717 & 0,818 & 0,520 & 0,955 & 0,469 & 0,750 \\
\hline \multicolumn{2}{|c|}{$A \times B$} & 0,753 & 0,930 & 0,436 & 0,174 & 0,736 & 0,087 & 0,672 \\
\hline
\end{tabular}

$\overline{\mathrm{A}, \mathrm{B}}$ Letras maiúsculas diferem na mesma coluna (entre os ingredientes) $(\mathrm{P}<0,05)$. 
Tabela 7. Número de primeira visita ao pote com a dieta A (n) e razão de ingestão (RI + erro-padrão) de cães alimentados com a dieta controle (DC) e $20 \%$ de gérmen desengordurado (20\% de GD)

\begin{tabular}{ccc} 
Dieta A x B & $\mathrm{n}^{\mathrm{a}}$ & RI da dieta A ${ }^{\mathrm{b}}$ \\
\hline DC x $20 \%$ de GD & $11^{*}$ & $0,34 \pm 0,04^{*}$ \\
\hline
\end{tabular}

Número de visitas ao pote com dieta A não difere pelo teste qui-quadrado e RI pelo teste-t $(\mathrm{P}>0,05)$. ${ }^{2}$ Número de visitas ao pote com a dieta $\mathrm{B}$ é obtido como 32 - $\mathrm{n}$. ${ }^{\mathrm{b}} \mathrm{RI}$ : [g ingeridas da dieta $\mathrm{A}$ ou

$\mathrm{B} / \mathrm{g}$ totais fornecidas $(\mathrm{A}+\mathrm{B})] \mathrm{x} 10$.

\section{DISCUSSÃO}

O gérmen de milho desengordurado é um coproduto energético que pode ser utilizado como alternativa ao milho. Geralmente, os coprodutos apresentam menor digestibilidade em relação aos cereais devido à maior concentração de PNA em sua composição e, portanto, sua influência no aproveitamento de nutrientes. Rostagno et al. (2005), ao analisarem a porcentagem de FDN e FDA do GD (30,36\% e 6,19\%, respectivamente) verificaram valores superiores aos encontrados no milho (11,2\% e 2,64, respectivamente). A ação da fibra insolúvel pode aumentar a taxa de passagem da digesta, o que contribui para a menor atuação das enzimas digestivas endógenas, e, dessa forma, reduzir a digestibilidade dos ingredientes (Vanderhoof, 1998). Esse efeito foi observado em estudos em que se avaliou a inclusão de PNA a dietas de cães, corroborando seu efeito negativo na digestibilidade dos nutrientes (Silva et al., 2016; Sabchuk et al., 2017).

Existem diversos fatores que podem influenciar na eficácia das enzimas exógenas, entre eles: a fonte enzimática, o processamento, a variabilidade do ingrediente, a interação com outros componentes da dieta e os fatores intrínsecos ao animal (Bedford e Schulze, 1998), desse modo é comum encontrar trabalhos com resultados divergentes. Os estudos mais explorados na literatura sobre esse assunto avaliaram carboidrases, complexos com amilases, proteases e lipases, ao utilizarem ingredientes com fatores antinutricionais ou alto teor de fibras, a fim de melhorar o aproveitamento dos nutrientes em dietas para cães (Villaverde et al., 2017).

No presente estudo, a inclusão de enzima teve efeito na digestibilidade da MS, da EB e da EM em todas as dietas, não sendo observada interação entre enzima e dieta. De acordo com os resultados das análises dos PNA das dietas, observaram-se valores de arabinoxilanos (solúveis e insolúveis) da DC $(3,1 \%)$ e $20 \%$ de GD $(3,3 \%)$ muito semelhantes, indicando, portanto, que houve substrato para atuação da enzima em ambas as dietas, o que explica o efeito de melhoria da digestibilidade dos nutrientes com a inclusão do complexo enzimático. Os resultados de melhora da digestibilidade ao incluir a enzima estão de acordo com os observados por Silva et al. (2016), ao utilizarem uma dieta à base de milho, com inclusão de até $20 \%$ de DDGS, combinado com xilanase, quando os autores verificaram melhora da digestibilidade da MS, da PB e MO.

O DDGS também é um coproduto do milho e possui perfil semelhante de PNA do gérmen de milho (em sua maioria arabinose e xilose). Em contrapartida, Risolia et al. (2019), ao avaliarem dietas com 20\% de DDGS suplementadas de xilanase e protease, não verificaram alteração na digestibilidade. Essa diferença pode ser atribuída, possivelmente, ao fato de a concentração enzimática ser inferior $(0,2 \mathrm{~g} / \mathrm{kg})$ à utilizada por Silva et al. (2016), 0,5g/kg. Por outro lado, Twomey et al. (2003) compararam dietas à base de arroz, sorgo e milho com e sem a inclusão de um complexo enzimático $(1000 \mathrm{~mL} /$ tonelada, xilanase, a-amilase, $\beta$-glucanase, hemicelulase, pectinase e endoglucanase) e não verificaram influência na digestibilidade dos nutrientes. Resultados semelhantes foram encontrados por Pacheco et al. (2014), ao avaliarem dietas com farelo de arroz integral com inclusão de um complexo enzimático (carboidrases, fitase $\mathrm{e}$ protease - 0,4 e $0,8 \mathrm{~g} / \mathrm{kg}$ de dieta), em que os autores não observaram diferença na digestibilidade ao incluírem o blend enzimático.

Alguns oligossacarídeos, como os arabinoxilanos, são importantes para a saúde intestinal, podendo atuar como prebióticos (Niewold et al., 2012). Com a fermentação desses oligossacarídeos no intestino, os produtos resultantes são fundamentais para determinar a microbiota, selecionando ou não bactérias com potencial benéfico. Além disso, eles podem atuar como fonte de energia para os enterócitos, como é o caso do ácido butírico, produto proveniente da fermentação dos oligossacarídeos. 
Segundo Hopkins et al. (2003), em experimento no qual avaliaram a fermentação in vitro de arabinoxilanos, os autores correlacionaram a fermentação desse oligossacarídeo com o desenvolvimento de bactérias do gênero Bacteroide, que são consideradas benéficas por produzirem metabólicos interessantes para funcionalidade intestinal, como ácido propiônico e acético. Estudos avaliando o perfil microbiológico das fezes dos animais devem ser promovidos, a fim de elucidar os mecanismos envolvidos.

A fermentação das fibras solúveis pela microbiota intestinal tem como resultado a produção de AGCC, incluindo acetato, butirato e propianato (Félix et al., 2010). No entanto, no presente estudo, não foram observadas diferenças entre as dietas quanto à produção de AGCC, com exceção do ácido propiônico, que teve sua concentração reduzida nas dietas GD. Isso possivelmente ocorreu em razão de o perfil da fibra do gérmen de milho ser insolúvel, a qual tem menor fermentabilidade, e de a taxa de absorção dos AGCC pela mucosa intestinal ser rápida (Swanson et al., 2002), o que pode ter subestimado a concentração desse parâmetro.

O ácido siálico, utilizado como parâmetro indicativo de agressão à mucosa intestinal (Pirgozliev et al., 2005), não foi alterado com a inclusão de GD nas dietas. Tal resultado pode indicar que o ingrediente não é nocivo à mucosa do trato gastrointestinal dos cães. Os animais que consumiram as dietas com inclusão do gérmen desengordurado apresentaram fezes com maior MSf, quando comparados aos animais da DC. Tal fato pode ser explicado em razão de que essa dieta apresentava maior teor de PNA insolúvel, assim, ao aumentar essa fração da fibra, a quantidade de água eliminada nas fezes diminui, resultando em fezes mais secas, conforme foi observado por Fahey et al. (1990) e Sabchuk et al. (2017). A ausência de efeito sobre escore fecal, $\mathrm{NH}_{3}$ e $\mathrm{pH}$ está de acordo com o observado por Félix et al. (2012) e Pacheco et al. (2014), em cujos estudos a inclusão de enzima exógena não influenciou nas características fecais.

Não foram encontrados na literatura trabalhos que avaliassem a palatabillidade do gérmen do milho desengordurado para cães. Moreira et al. (2002) relatam que o farelo de gérmen de milho desengordurado apresenta boa palatabilidade em suínos. Outro fator a ser considerado foi que a ligeira maior inclusão de óleo de vísceras de aves, associada à boa aceitação dos animais pelo DDGS, propiciou maior preferência pela dieta GD. A maior preferência alimentar e a primeira escolha pelo gérmen de milho desengordurado no presente estudo não puderam ser atribuídas a uma causa específica, pois a palatabilidade é influenciada por vários fatores. Entre eles, estão as características organolépticas do alimento, a impressão social e o comportamento neofílico dos animais (Félix et al., 2010). Portanto, estudos são importantes para entender o papel do gérmen do milho desengordurado na palatabilidade na dieta de cães neofóbicos.

\section{CONCLUSÃO}

Os cães preferiram a dieta com $20 \%$ de gérmen de milho desengordurado em relação à dieta controle. Ainda, a inclusão do gérmen de milho desengordurado em dietas para cães em substituição ao milho reduz a digestibilidade e a EM da dieta. A adição de um complexo enzimático contendo carboidrases melhora o aproveitamento da energia em dietas para cães.

\section{REFERÊNCIAS}

ASSOCIATION OF AMERICAN FEED CONTROL OFFICIALS. Dog and cat nutrient profiles. Official Publications of the Association of American Feed Control Officials Incorporated. AAFCO, Oxford, IN, USA, 2008.

ASSOCIATION OF THE OFFICIAL ANALYTICAL CHEMISTS. Official Methods of Analysis. 16th ed. AOAC, DC, USA, 1995.

BEDFORD, M.R.; SCHULZE, H. Exogenous enzymes for pigs and poultry. Nutr. Res. Rev., v.11, p.91, 1998.

CARCIOFI, A.C. Fontes de proteína e carboidratos para cães e gatos. Rev. Bras. Zootec., v.37, p.28-41, 2008.

CARCIOFI, A.C.; OLIVEIRA, L.; VALÉRIO, A. et al. Comparison ofmicronized whole soybeans to common protein sources in dry dog and cats diet. Anim. Feed Sci. Techonol., v.151, p.251-256, 2009.

COWIESON, A.J.; ADEOLA, O. Carbohydrases, protease, and phytase have an additive beneficial effect in nutritionallymarginal diets for broiler chicks. Poult. Sci., v.84, p.1860-1867, 2005. 
ENGLYST, H.; WIGGINS, H.S.; CUMMINGS, J.H. Determination of the non-starch polysaccharides in plant foods bygas-liquid chromatography of constituent sugars as alditol acetates. Analyst., v.107, p.307-318, 1982.

FAHEY, G.C.; MERCHEN, N.R.; CORBIN, J.E. et al. Dietary fiber for dogs 2: Iso-total dietary fiber (TDF) additions of divergent fiber sources to dog diets and their effects on nutrient intake, digestibility, metabolizable energy and digestmean retention time. J. Anim. Sci., v.68, p.4221-4228, 1990.

FÉLIX, A.P.; CARVALHO, M.P.; ALARÇA, L.G. et al. Effects of the inclusion of carbohydrases and diferente soybeanmeals in diet on palatability, digestibility and faecal characteristics in dogs. Anim. Feed Sci. Technol., v.174, p.182-189, 2012. FÉLIX, A.P.; TEXEIRA NETTO, M.V.; MURAKAMI, F.Y. et al. Digestibility and fecal characteristics of dogs fed with Bacillus subtilis in diets. Cienc. Rural., v.40, p.2169-2173, 2010.

HOPKINS, M.J.; ENGLYST, H.N.; MACFARLANE, S. et al. Degradation of crosslinked and non-cross-linked arabinoxylans by the intestinalmicrobiota in children. Appl. Env. Microbiol., v.69, p.6354-6360, 2003.

JOURDIAN, G.W.; DEAN, L.; ROSEMAN, S. Ummétodo de periodato-resorcinol para a estimativa quantitativa de ácidos siálicos livres e seus glicosídeos. J. Biol. Chem., v.246, p.430-435, 1971.

MOREIRA, I.; RIBEIRO, C.R.; FURLAN, A.C. et al. Utilização do farelo de germe de milho desengordurado na alimentação de suínos em crescimento e terminação: digestibilidade e desempenho. R. Bras. Zootec., v.31, p.2238-2246, 2002.

NIEWOLD, T.A; SCHROYEN, M.; GEENS, M.M.; VERHELST, R.S.B. et al. Dietary inclusion of arabinoxylan oligosaccharides (AXOS) down regulates mucosal responses to a bacterial challenge in a piglet model. J. Funct. Foods., v.4, p.626-635, 2012.

NRC. Requirements of Dogs and Cats. NRC, Natl. Acad. Press, Washington, DC, USA, 2006.

PACHECO, G.F.E.; MARCOLLA, C.S.; MACHCADO, G.S. et al. Effect of full-fat rice bran on palatability and digestibility of diets supplemented with enzymes in adult dogs. $J$. Anim. Sci., v.92, p.4598-4606, 2014.
PATIENCE, J.F.; THACKER, P.A.; LANGE, C.F.M. Swine nutritionguide. Prairie Swine Centre., v.2, p.274, 1995.

PIRGOZLIEV, V.; SHANMUGAVELU, S.; ACAMOVIC, T. Effect of themethod of drying on the concentration of sialic acid in poultry excreta. Poult. Sci. Assoc., v.2005, p.536-538, 20005.

RISOLIA, L.W.; SABCHUK, T.T.; MURAKAMI, F.Y.; FÉLIX, A.P. et al. Effects of adding distillers dried grains with solubles (DDGS) in dog diets supplemented with xylanase and protease. R. Bras. Zootec., v.48, p.e20190112, 2019.

ROSTAGNO, H.N.; ALBINO, L.F.T.; DONZELE, J.L.; GOMES, P.C. et al. Tabelas brasileiras para aves e suínos (composição de alimentos e exigências nutricionais). Viçosa, MG: UFV, 2005. 186p.

SABCHUK, T.T.; LOWNDES, F.G.; SCHERAIBER, M. et al. Effect of soya hulls on diet digestibility, palatability and intestinalgas production in dogs. Anim. Feed Sci. Technol., v.225, p.134-142, 2017.

SILVA, J.R.; SABCHUK, T.T.; LIMA, D.C. et al. Use of distillers driedgrains with solubles (DDGS), with and without xylanase, in dog food. Anim. Feed Sci. Technol., v.220, p.136-142, 2016.

SWANSON, K.S.; GRIESHOP, C.M.; FLICKINGER, E.A.; BAUER, J.C. et al. Fructooligoscharides and Lactobacillus acidophilus modifygutmicrobial populations, total tract nutrient digestibilities and fecal protein catabolite concentrations in healthy adult dogs. $J$. Nutr., v.132, p.3721-3731, 2002.

TWOMEY, L.N.; PLUSKE, J.R.; ROWE, J.B.; CHOCT, M. et al. The replacement value of sorghum andmaize with or without supplemental enzymes for rice in extruded dog foods. Anim. Feed Sci. Technol., v.108, p.61-69, 2003.

VANDERHOOF, J. Immunonutrition: the role of carbohydrates. Nutr., v.14, p.595-598, 1998.

VILLAVERDE， C.; MANZANILLA， E.G.; MOLINA, J.; LARSEN, J.A. Effect of enzyme supplements onmacronutrient digestibility by healthy adult dogs. J. Nutr. Sci., v.6, p.12, 2017. 
Arq. Bras. Med. Vet. Zootec., v.73, n.1, p.239-246, 2021 